\title{
Examination optical education role of university for optical industry and efforts at Chiba Institute of Technology
}

Y. Fujimoto, K. Wakita, K. Suizu

Y. Fujimoto, K. Wakita, K. Suizu, "Examination optical education role of university for optical industry and efforts at Chiba Institute of Technology," Proc. SPIE 11143, Fifteenth Conference on Education and Training in Optics and Photonics: ETOP 2019, 111431V (2 July 2019); doi: 10.1117/12.2523833 Photonics: ETOP 2019, 2019, Quebec City, Quebec, Canada 


\title{
Examination optical education role of university for optical industry and efforts at Chiba Institute of Technology
}

\author{
Y. Fujimoto ${ }^{a}, K$. Wakita ${ }^{a}, K$. Suizu ${ }^{b}$ \\ ${ }^{a}$ Dept. of Electrical and Electronic Engineering, Chiba Institute of Technology (CIT), ${ }^{b}$ Dept. of \\ Information and Communication Systems Engineering, Chiba Institute of Technology (CIT), 2-17-1 \\ Tsudanuma, Narashino, Chiba, 275-0016, JAPAN
}

\begin{abstract}
As announced the other day, the 2018 Nobel Prize in Physics was given for the development of optical tweezers and ultrashort pulse lasers. Optical technology is constantly advancing and penetrating into various industrial fields. Recently, the power of fiber lasers is remarkably increasing, and therefore, it becomes a promising processing tool for metalworking and its marketing value is also increasing. In addition, now we already have many processes that cannot be done without laser, and this trend will continue in the future. However, we often hear from potential users of optical technology who work at machining, "I understand the importance of optical technology, but I am hesitating to introduce because I do not know how to use". This is the same from the actual feeling as an optical researcher of me, and I feel the lack of optical engineers who realize new technological ideas. In other words, the current state of the industry is in short supply of optical engineers. As a factor of short supply of optical engineers, mostly optical education is often in charge of the Department of Electrical and Electronic Engineering, Faculty of Engineering at Japanese universities, and therefore, most of the students that have learnt optics are employed as electrical/electronic engineers after graduation. Meanwhile, it is also true that efforts to resolve at various universities have begun. While introducing our optical education (student experiment: Control of polarization state), we will examine optical education at university and its role for the optical industry.
\end{abstract}

Keywords: Optical education, Optical industry, Training optical engineers, Benefit sharing community

\section{INTRODUCTION}

Optical technology is widely used in industrial applications and research fields such as laser processing, consumer products of DVD, displays, barcodes, and advanced measurement in medical or material research. The laser invented by T. H. Maiman in 1960 plays a major role in the development of these optical technologies.

The recent 2018 Nobel Prize in Physics was awarded for the development of optical tweezers and its application to biological systems, as well as for the development of ultra-high power, ultra-short pulse lasers. Since the invention of lasers, optical and laser technology has been developing rapidly, and new technologies have always been created, and accordingly, the optical technology has penetrated and used in various fields. I have been engaged in research on optical technology such as laser material development, optical fiber and fiber laser development so far [1-4], and I have no doubt about its development and possibility.

Figure 1 shows the transition of the total shipment value in the field of laser processing in Japan. Until now, carbon dioxide gas lasers have often been used for metal processing, but with the recent increase in output of fiber lasers, replacement with fiber lasers has progressed. Since the fiber laser is capable of finer processing, the spread to new processing applications is also helped, and the shipping amount has been increased. There are already many processes that cannot be done without using laser light, and therefore, this trend is expected to continue. 


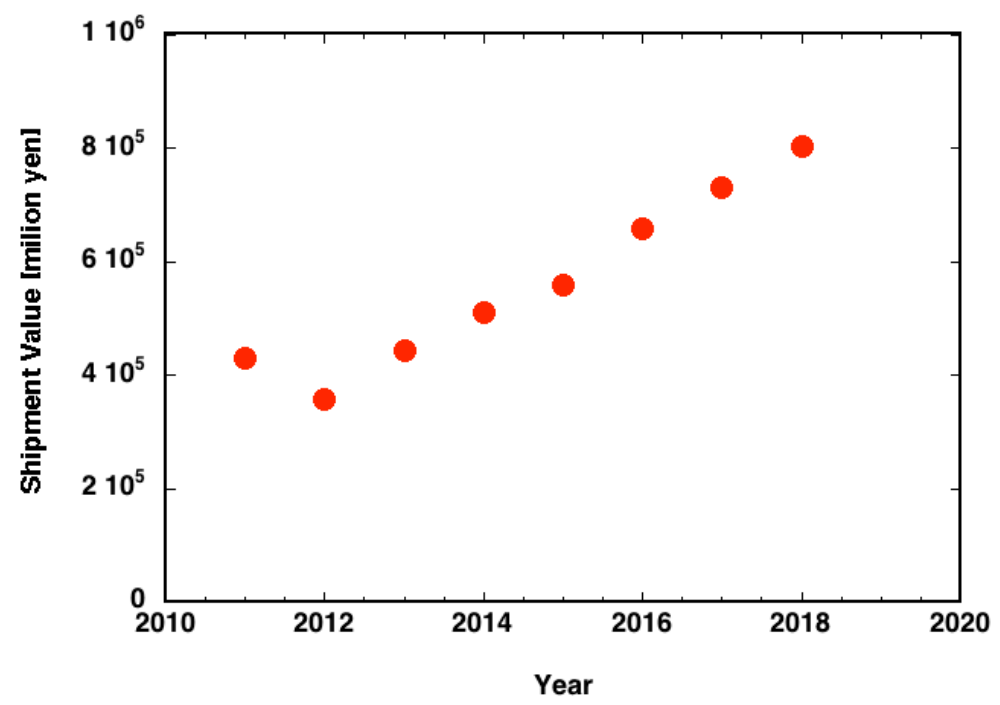

Figure 1. the transition of the total shipment value in the field of laser processing in Japan

Although optical research in universities and research institutes in Japan is active, and there are many leading researches in the world, I often hear from potential users who make machining a living by saying, " I understand the importance of laser technology, but I am hesitant to introduce it because I do not know how to use it". In addition, there is an overwhelming shortage of optical engineers who realize the idea of new optical technology from the feeling as an optical researcher in the past 30 years. Therefore, it is thought that advanced research results in optics are not transmitted efficiently. Because the absolute number of engineers in the middle layer is small as shown in Figure 2, if we try to connect the demands of each other, we will be quite unreasonable to cooperate with each other.

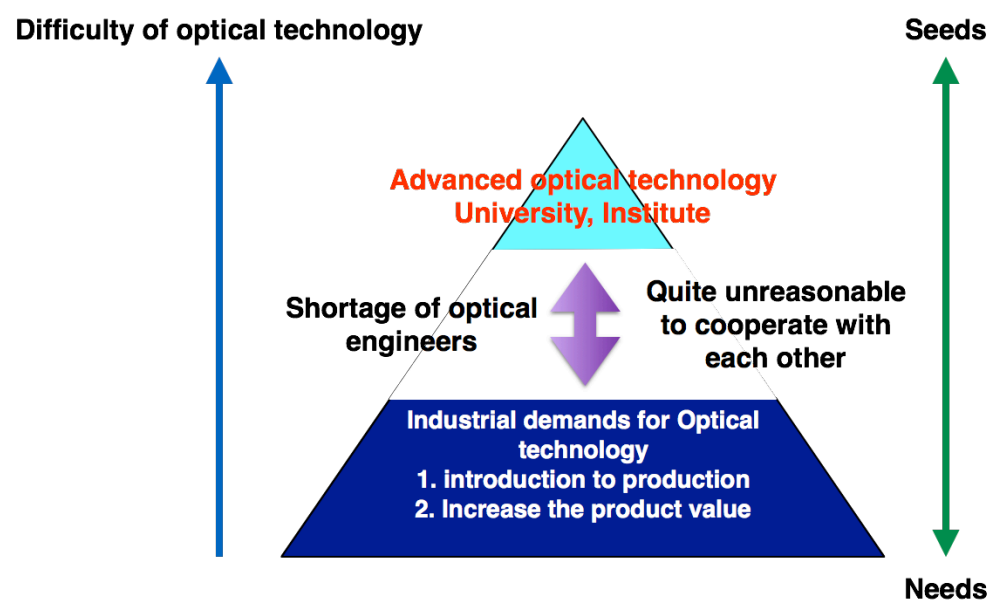

Figure 2. The shortage of optical engineers in the middle layer in Japan

In this study, we aim to understand the causes of the gap between advanced optical research and optical industry, and to explore its solutions from the perspective of light education. We show the concept of " benefit sharing community " as one proposal, and think about its way. We also introduce our university's optical education activities. We believe that these findings will bring about the bringing up of optical engineers and the development of the optical industry. 


\section{OPTICAL EDUCATION ROLE OF UNIVERSITY FOR OPTICAL INDUSTRY}

\subsection{The concept of benefit sharing community}

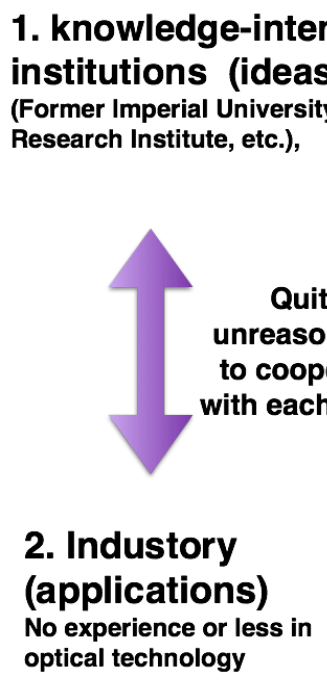

Figure 3. Conceptual view of benefit sharing community in optical science and technology development

When we cultivate engineers who have not only optical technology but also advanced knowledge, referring to the theory of education, researchers and engineers with advanced technical knowledge in each field will provide specialized education to beginners. However, research on educational methods cannot provide insights into the gap between the current social demands (lack of optical engineers). Since electrical and electronic engineering, mechanical engineering, chemical engineering, etc. are older than optical engineering, it is thought that they have built up a pyramid of industrial development and human resources composition in its long development history. In the field of optical engineering, it can be expected to develop in the same way if it takes many years.

Figure 3 embodies one of the solutions that I imagine. In other words, the benefit sharing community becomes an agency that links knowledge-intensive institutions (National University, National Research Institute, etc.), industry, human resources (for example, middle-level private university students), and human resources development institutions (for example, middle-level private university). Although the concrete form of this benefit sharing community has not been completed at this time, I would like to propose a concrete form while organizing and analyzing the situation in the future.

\subsection{Positioning by standard score of Chiba Institute of Technology}

There are 782 universities, where 603 schools (77.1\%) are private university, in Japan in 2018 [6]. Chiba Institute of Technology is a private college with five faculties and 17 departments [7]. Figure 4 shows the position of Chiba Institute of Technology in the Standard score (T score) data of university entrance examination in Japan in 2018 [8]. As can be seen from the figure, Chiba Institute of Technology is in charge of education of the most populated part of the total number of students in Japan at the academic level, and is located at a middle-level private university in the benefit sharing community shown in Figure 3. It is considered possible to develop human resources who are most lacking in developing optical technology or its application. However, we have to note that the standard scores are just indicators and do not fix the student's academic situation. Students can change their active status by their motivation and effort. 


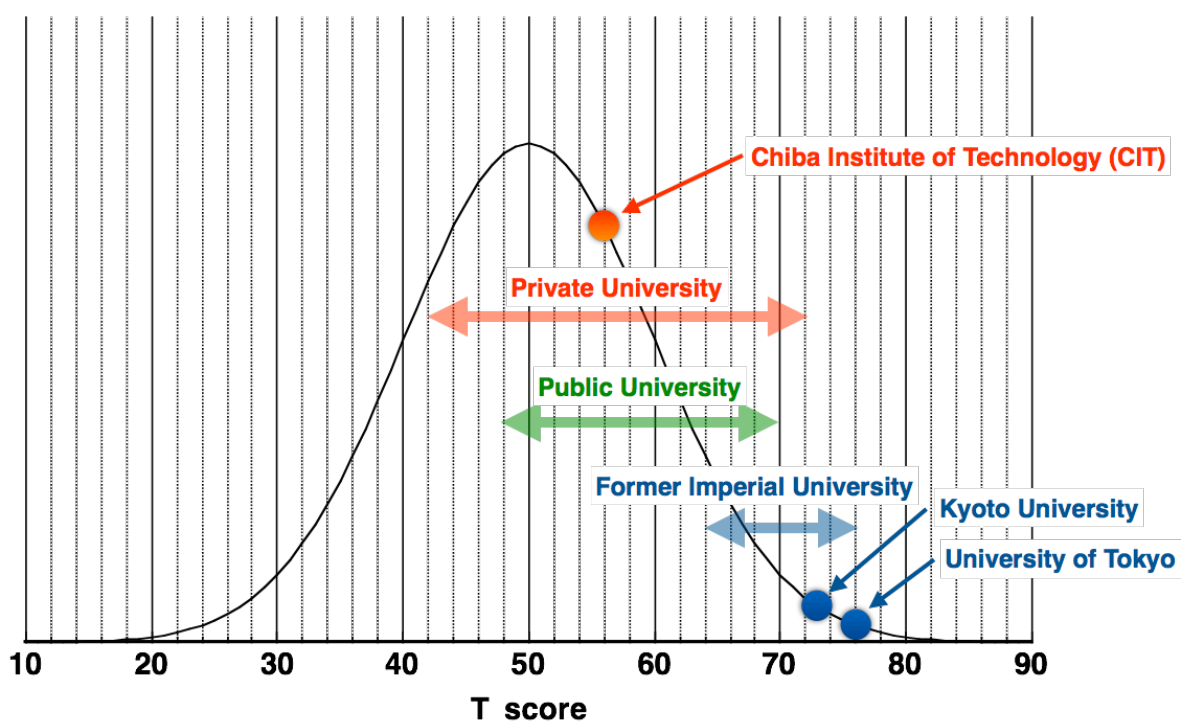

Figure 4. Standard score (T score) data of university entrance examination in Japan in 2018

\subsection{Optical education at universities in Japan}

Optical education at universities in Japan is often carried out by faculty members of the Department of Electrical and Electronic Engineering and related departments. The same is true for Chiba Institute of Technology, and professors in the Department of Electrical and Electronic Engineering and Information and Communication Systems Engineering are in charge of optical education. However, few universities have a department for optical technology education. Also, the academic society plays an educational role, and the following shows the university with optics department and the academic society of optics.

1) University

$\checkmark$ Utsunomiya University, School of Engineering, The Information, Electronics and Optics Course

$\checkmark$ Kochi University of Technology, School of Systems Engineering, Electronic and Photonic Engineering

$\checkmark$ Tokai University, School of Engineering, Department of Optical and Imaging Science and Technology

$\checkmark$ Chitose Institute of Science and Technology, Graduate school of Photonic Science

$\checkmark \quad$ The Graduate School for the Creation of New Photonics Industries

$\checkmark$ Others

2) Societies of Education

$\checkmark$ Japanese Educational Research Association

$\checkmark$ Japan Association for College and University Education

$\checkmark$ ETOP (Education and Training in Optics and Photonics :OSA)

$\checkmark$ Others

3) Societies of Optical Technology

$\checkmark$ The Laser Society of Japan

$\checkmark$ The Optical Society of Japan

$\checkmark$ Others 


\section{EFFORTS AT CHIBA INSTITUTE OF TECHNOLOGY}

After conducting solid-state laser material, optical fiber and fiber laser development for about 30 years, I joined the Chiba Institute of Technology, Department of Electrical and Electronic Engineering in April 2017 as a full-time professor, and operate research activities and laboratories. The main research themes are "Development of special fiber laser using new optical material and its industrial application and training of optical industry and optical science education".

\subsection{Optical education in my laboratory}

I am teaching students (13 third graders, 13 fourth graders, and one graduate student in 2019). Fourth graders and graduate students are developing special fiber lasers at graduation research, and I am conducting research and guidance on basic techniques of fiber lasers and optical measurement. I am teaching third graders knowledge about optical technology and basic optical experimental technology using Amnon Yariv "Introduction to optical electronics" etc.

\subsection{Optical lectures in the Department of Electrical and Electronic Engineering}

I am in charge of the following lectures for students in the department of electrical and electronic engineering. The Advanced Optoelectronics syllabus, which is a graduate course subject, listened to opinions from company people related to optical technology (12 companies) and picked up items that are mostly requested. Optoelectronics and Advanced Optoelectronics can update syllabus once a year, so I can build-up the lecture material reflecting social needs. The syllabuses that I teach as follows.

1) Optoelectronics

- Target students: $6^{\text {th }}$ semester of $3^{\text {rd }}$ year of bachelor degree

- Goal of understanding:
$\checkmark \quad$ The relationship between light and electromagnetic waves and their propagation
$\checkmark \quad$ The nature of light and the optical elements and devices that control the light
$\checkmark \quad$ The technologies that make up laser sources and devices, and the latest optical technologies and applications

Table 1 Syllabus of Optoelectronics

\begin{tabular}{|c|l|}
\hline Week & Contents \\
\hline $1^{\text {st }}$ & Guidance \\
\hline $2^{\text {nd }}$ & Electromagnetic waves and wave equation \\
\hline $3^{\text {rd }}$ & Electromagnetic waves and light energy flow (Poynting vector) \\
\hline $4^{\text {th }}$ & Duality of light (particle and wave) \\
\hline $5^{\text {th }}$ & Polarization of light and its handling \\
\hline $6^{\text {th }}$ & Types of polarizing elements, Their properties and usage \\
\hline $7^{\text {th }}$ & Fundamentals of the interaction between light and matter \\
\hline $8^{\text {th }}$ & Application of the interaction between light and matter \\
\hline $9^{\text {th }}$ & $<$ Midterm examination $>$ \\
\hline $10^{\text {th }}$ & Ray propagation and ray matrix (ABCD matrix) \\
\hline $11^{\text {th }}$ & Active optics and nonlinear optical effects \\
\hline $12^{\text {th }}$ & Optical amplification and laser \\
\hline $13^{\text {th }}$ & How to make a laser device \\
\hline $14^{\text {th }}$ & Various laser devices and optical fibers and fiber lasers \\
\hline $15^{\text {th }}$ & $<$ Term-end examination> \\
\hline & \\
\hline
\end{tabular}

2) Advanced Optoelectronics

- Target students: master degree

- Goal of understanding: 
Theories related to cutting-edge light technology and their applications

Optical element handling, measurement methods, optics and equipment design

The latest optical research, companies and products related to laser light sources and devices

Table 2 Syllabus of Advanced Optoelectronics

\begin{tabular}{|c|l|}
\hline Week & Contents \\
\hline $1^{\text {st }}$ & Guidance \\
\hline $2^{\text {nd }}$ & Optical theory overview \\
\hline $3^{\text {rd }}$ & Geometrical optics theory \\
\hline $4^{\text {th }}$ & Introduction to practical geometric optics \\
\hline $5^{\text {th }}$ & Wave optics theory \\
\hline $6^{\text {th }}$ & Quantum optics theory \\
\hline $7^{\text {th }}$ & Optical simulation technology \\
\hline $8^{\text {th }}$ & Optical measurement technology \\
\hline $9^{\text {th }}$ & Optical design and manufacturing technology \\
\hline $10^{\text {th }}$ & Presentation 1 \\
\hline $11^{\text {th }}$ & Pick-up 1 of the state-of-the-art optical research and technology \\
\hline $12^{\text {th }}$ & Pick-up 2 of the state-of-the-art optical research and technology \\
\hline $13^{\text {th }}$ & Pick-up 1 of the cutting-edge optical industry \\
\hline $14^{\text {th }}$ & Pick-up 2 of the cutting-edge optical industry \\
\hline $15^{\text {th }}$ & Presentation 2 \\
\hline
\end{tabular}

3) Electrical and Electronic Engineering laboratory 3 (Polarization state control)

- Target students: $6^{\text {th }}$ semester of $3^{\text {rd }}$ year of bachelor degree

- Goal of understanding:

$\checkmark \quad$ Laser polarization characteristics (Malus's law)

$\checkmark$ Characteristics of half and quarter wave plate

$\checkmark \quad$ Observation of polarization state change by inserting a plastic film and compensating it by wave plates

\subsection{Optical lectures example}

\section{1) Advanced Optoelectronics}

As mentioned above, the main purpose of optical education at Chiba Institute of Technology is to train optical engineers in the middle class. Therefore, in addition to lectures, practice using experimental equipment is incorporated. In fiscal 2019 , it is structured to understand the items described in the syllabus through experiments of second harmonic generation using a KTP crystal. The experimental diagram is shown in the figure 5. In addition, items in the syllabus are rearranged by introducing the practice (Table 3 ).

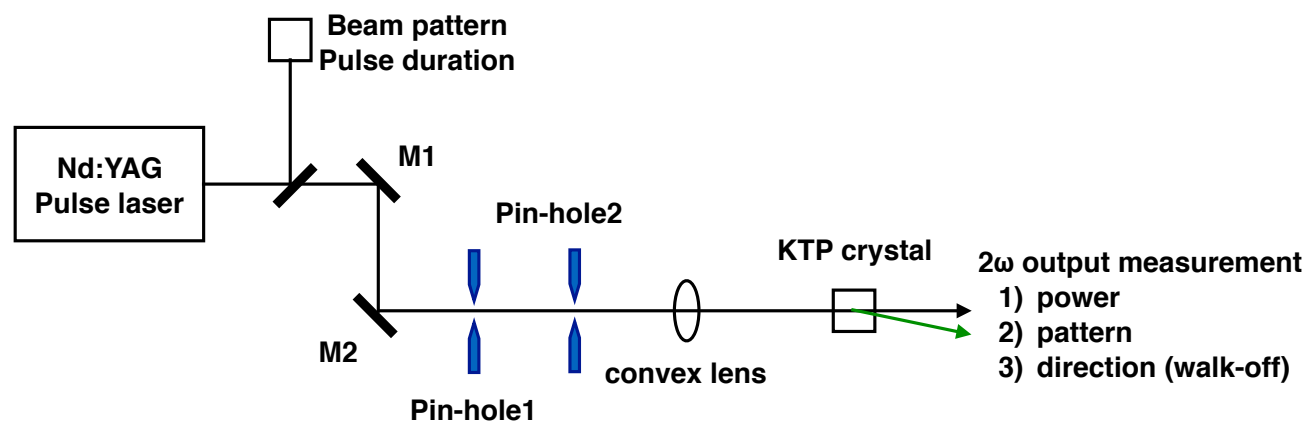

Figure 5. Second harmonic generation experimental setup for Advanced Optoelectronics 
Table 3 Modified syllabus of Advanced Optoelectronics ( $2^{\text {nd }}$ to $9^{\text {th }}$ week $)$

\begin{tabular}{|c|c|c|}
\hline Week & Contents & \\
\hline $1^{\mathrm{st}}$ & Guidance & Laser safety \\
\hline $2^{\text {nd }}$ & $\begin{array}{l}\text { Optical theory overview, } \\
\text { practice geometric optics } \\
\text { general theory }\end{array}$ & $\begin{array}{l}\text { Optical elements handling (how to clean optics), } \\
\text { alignment method with time trial }\end{array}$ \\
\hline $3^{\text {rd }}$ & $\begin{array}{l}\text { Geometrical optics theory, } \\
\text { wave optics theory }\end{array}$ & $\begin{array}{l}\text { Optical system design by ABCD matrix; both of } \\
\text { geometric optical and wave optical) }\end{array}$ \\
\hline $4^{\text {th }}$ & $\begin{array}{l}\text { Wave optics theory, quantum } \\
\text { optics theory }\end{array}$ & $\begin{array}{l}\text { Principle of second harmonic generation, indicatrix, } \\
\text { requirement of KTP crystal specifications, calculation of } \\
\text { phase matching angle }\end{array}$ \\
\hline $5^{\text {th }}$ & $\begin{array}{l}\text { Optical design and } \\
\text { manufacturing technology }\end{array}$ & Mechanism design and specifications \\
\hline $6^{\text {th }}$ & $\begin{array}{l}\text { Optical measurement } \\
\text { technology }\end{array}$ & $\begin{array}{l}\text { Fundamental laser characteristics; beam pattern } \\
\text { measurement by CCD, pulse width, focal spot size } \\
\text { depending on a lens focal length }\end{array}$ \\
\hline $7^{\text {th }}$ & $\begin{array}{l}\text { Optical measurement } \\
\text { technology }\end{array}$ & $\begin{array}{l}\text { Polarization measurement, second harmonic generation } \\
\text { experiment, walk-off }\end{array}$ \\
\hline $8^{\text {th }}$ & Optical simulation technology & $\begin{array}{l}\text { Simulation on the third week optical system by CODE- } \\
\text { V }\end{array}$ \\
\hline $9^{\text {th }}$ & $\begin{array}{l}\text { Wave optics theory, quantum } \\
\text { optics theory }\end{array}$ & $\begin{array}{l}\text { Summarizing second harmonic generation experiment } \\
\text { and making presentation materials }\end{array}$ \\
\hline $10^{\text {th }}$ & Presentation 1 & \\
\hline
\end{tabular}

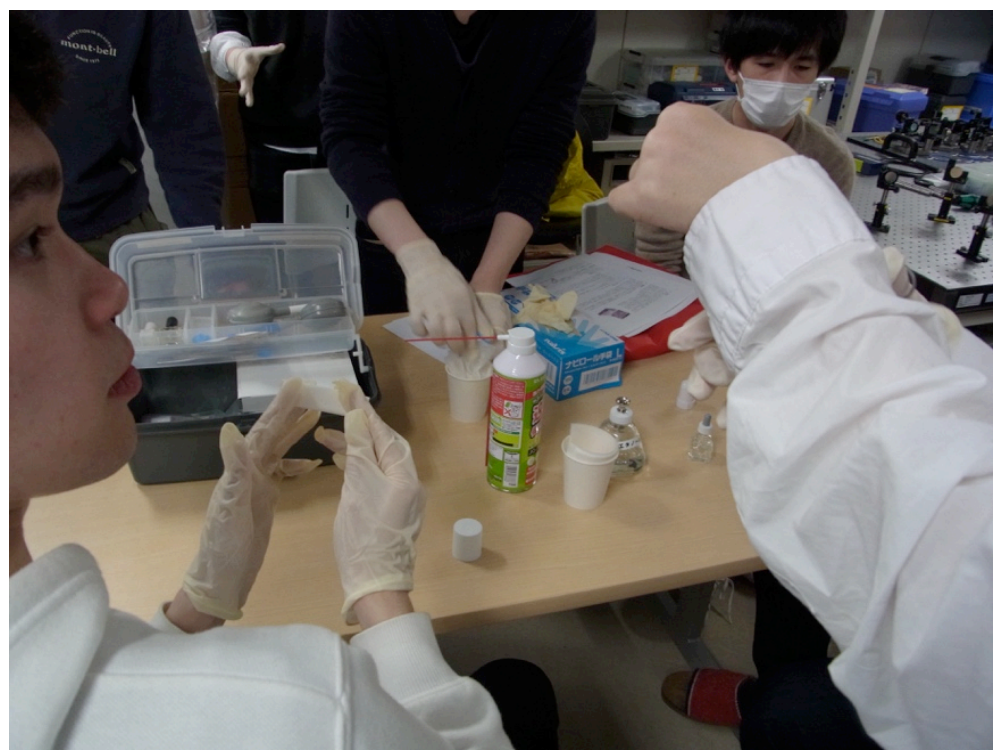

Figure 6. A photograph of students learning how to clean optics 


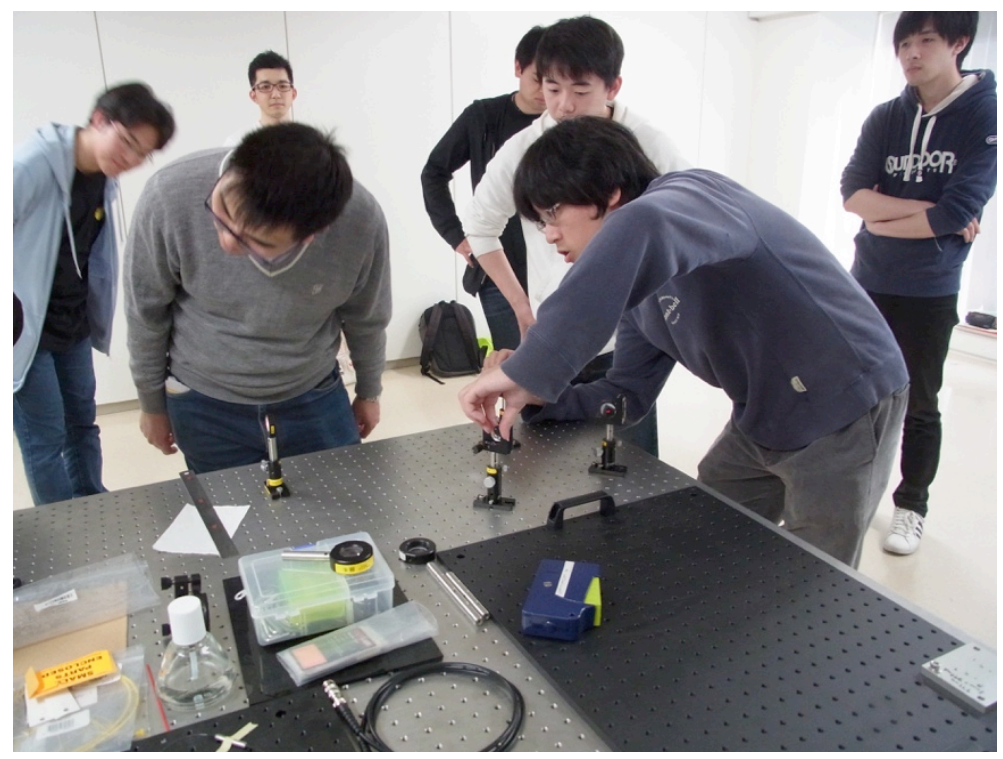

Figure 7. A photograph of students learning how to align optics (straight through two pin-holes).

2) Electrical and Electronic Engineering laboratory 3 (Control of polarization state)

I am in charge of "Control of polarization state" as one of the 10 items of "Electrical Electronics Experiment 3". The polarization state is one of the important physical parameters for light control. The experimental drawing is shown below.

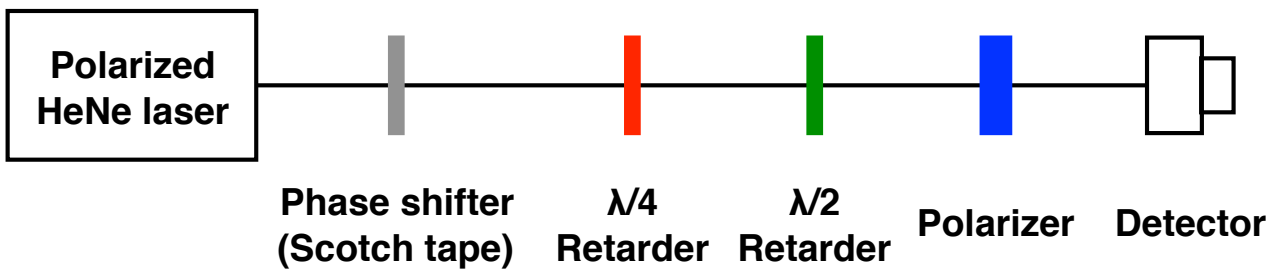

Figure 8. Experimental setup for polarization state control

\section{$\checkmark \quad$ Laser polarization characteristics (Malus's law)}

Using a polarized HeNe laser and a polarizer, the polarizer is varied from 0 to 180 degrees and the beam intensity of the transmitting $\mathrm{HeNe}$ laser is plotted with the angle on the horizontal axis. It is measured that the Malus's law holds between the rotation angle of the polarizer and the equivalent beam intensity.

$$
I=I_{0} \cos ^{2} \psi
$$

$\checkmark \quad$ Characteristics of half and quarter wave plate

Using a polarized HeNe laser, a polarizer and a half or a quarter wave plate, students set the angles of a half or a quarter wave plate to 0 degree, 22.5, 45 degrees, change the polarizer from 0 to 180 degrees, and plot the transmitted HeNe laser beam intensity with the angle as the horizontal axis. Students measure that the half wave plate rotates the polarization direction and the quarter wave plate changes the linearly polarized light into elliptically polarized light and circularly polarized light. 
$\checkmark \quad$ Observation of polarization state change by inserting a plastic film and compensating it by wave plates

Using a polarized HeNe laser, a polarizer and a plastic film, the plastic film has birefringence. A plastic film is inserted between the laser and the polarizer, the angle of the linear polarizer is changed from 0 degrees to 180 degrees, and the relationship between the angle and the light output is measured. Elliptical polarization due to birefringence is observed. Next, a quarter wave plate is inserted behind the plastic film and adjusted to correct elliptical polarization to linear polarization.

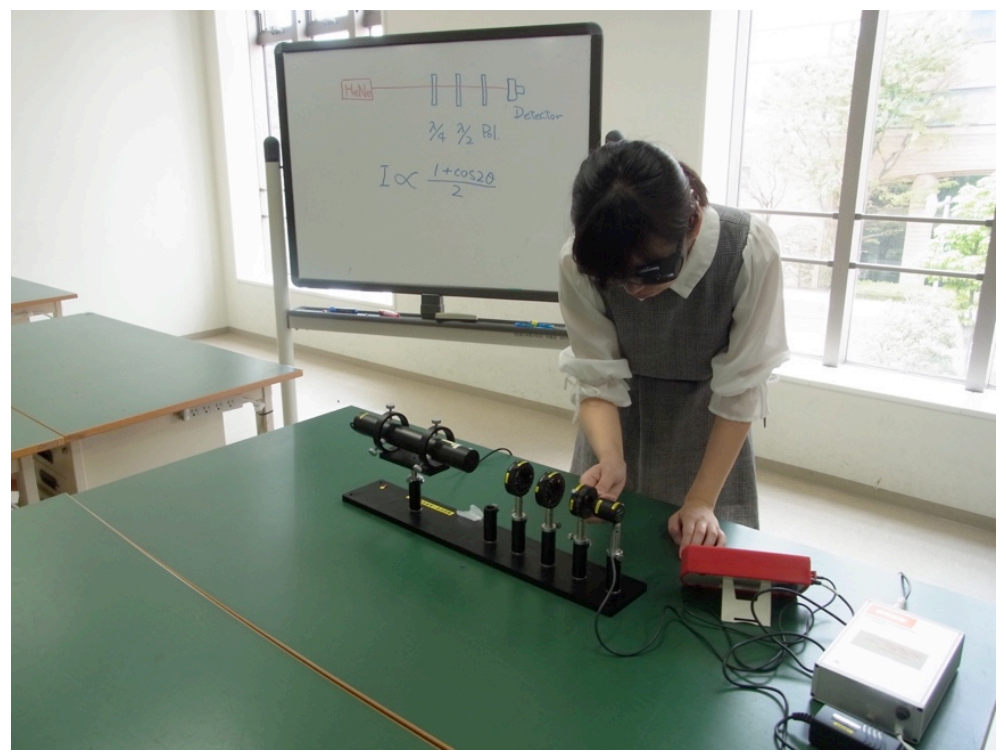

Figure 9. A photograph of a student learning "Polarization state control" in Electrical and Electronic Engineering laboratory 3

\section{DISCUSSION}

What we want to know is what corresponds to the benefit sharing community shown in Figure 2. And even if it is small, we will construct a benefit sharing community and consider matching it with optical education at Chiba Institute of Technology. For that purpose, we consider the following methods.

1) Grasp the current situation in each group

First of all, we have to know the current efforts, measures and problems in the knowledge-intensive institutions (National Univ., National Research etc.), industry, human resources (for example, mid-level private university students), human resources development (for example, mid-level private university education). We are going to collect the opinions of the knowledge-intensive institutions from researchers who participate in a society (Applied Physics Society, Laser Society, Japan Optical Society, OSA etc.) and the opinions of company people who participate exhibitions (OPIE, light and laser science and technology fair, CLEO etc.). In addition, we also collect as many opinions as possible in questionnaire form interviews from students and university educators who are active in optical technology education. And then we take a comprehensive review of these tabulated results and get an overview of the true identity of the benefit sharing community.

\section{2) Identification of inhibitory factors in fostering optical engineers}

We investigate the minds of people who are optical engineers and potential optical engineers who may become such in the future. For example, general students will have, "Does optical study help?" "Do you have work ahead?" Then business people will have "If you learn optics, will your treatment improve?" The power of women is important in the future because of the declining birth rate, but there are concerns such as when women become optical engineers. In addition, the industry is concerned about the introduction of optical technology, for example, "the place where you can educate optical engineers on your own is good, but the place you want to enter new areas has a higher threshold." or "The problem is that the population is small from the beginning," etc. As a factor of short supply of optical engineers, it is considered that mostly optical education is often in charge of the Department of Electrical and Electronic Engineering, 
Faculty of Engineering at Japanese universities, because even if the students have learned optics, they receive their job offers after graduation as mainly electrical/electronic engineers. Considering above situation, we investigate and organize the inhibitory factors that each one has.

3) Proposal of benefit sharing community realization method

Based on the surveys in 1) and 2), we propose a method for realizing the benefit sharing community, and make a presentation at a conference etc. In addition, we will hear the opinions of the interviewees directly, make corrections, and embody the form of the benefit sharing community. We repeat the procedure of 1) to 3) several times to summarize the concrete form of the benefit sharing community and its realization method.

\section{CONCLUSION}

There have always been doubts as we have done cutting-edge optical research so far. I think that research must always be useful to the world. In conducting research, it is very important to do the world's first and the best in the world, and there is no doubt this. However, even if it is the world's first and the world's best, it is important whether organic progress can be seen from the viewpoint of science and technology. I would like to consider if this benefit sharing community is useful for optical science development and how it will work well.

\section{REFERENCES}

[1] Y. Fujimoto, M. Nakatsuka, A novel method for uniform dispersion of the rare earth ions in $\mathrm{SiO}_{2}$ glass using zeolite X, J. Non·Cryst. Solids, 215, 182-191 (1997).

[2] M. Murakami, Y. Fujimoto, S. Motokoshi, T. Sato, H. Shiraga, Short-length fiber laser oscillation in 4-mm Nddoped silica fiber fabricated by zeolite method, Opt. Commun., 328, 121-123 (2014).

[3] Y. Fujimoto, M. Nakatsuka, Infrared luminescence from bismuth-doped silica glass, Japanese Journal of Applied Physics Part 2-Letters, 40, L279-L281 (2001).

[4] Y. Fujimoto, J. Nakanishi, T. Yamada, O. Ishii, M. Yamazaki, Visible fiber lasers excited by GaN laser diodes, Progress in Quantum Electronics, 37, 185-214 (2013).

[5] Optoelectronics Industry and Technology Development Association” Annual Technical Report”, http://www.oitda.or.jp/index-e.html

[6] School basic survey, universities and graduate schools, Statistics of Japan, https://www.e-stat.go.jp/en

[7] Homepage of Chiba Institute of Technology, https://www.it-chiba.ac.jp

[8] Standard score data of university entrance examination in Japan in 2018 by Benesse Corporation: https://manabi.benesse.ne.jp/daigaku/ 